\title{
O estado contemporâneo, a atividade jurisdicional e a realização de políticas públicas: a (re)construção de uma realidade social
}

Cassiana Alvina Carvalho ${ }^{1}$

\section{Resumo}

O Estado contemporâneo enfrenta problemas de efetividade que muitas vezes se apresentam na forma de prestação de serviços que garantam um mínimo de dignidade aos cidadãos sob sua jurisdição. Esse sistema prestacional muitas vezes se resolve por meio de políticas públicas que, frente a um Estado Provedor insuficiente e o aumento vertiginoso das demandas, passa a "Estado-julgado", sendo que os limites desse julgamento estão insertos nas Cartas Políticas de cada Estado como forma de limites e possibilidades.

Palavras-chave: Estado, Políticas públicas. Dignidade. Cidadãos.

\section{Introdução}

Está-se vivenciando a formação de uma nova ordem no campo político, social, jurídico, empresarial e em todas as demais áreas de ingerência do ser humano. Novas necessidades surgem em todos os campos com urgência ímpar. E em tal contexto, o presente estudo terá como norte a busca pela efetivação das necessidades básicas da sociedade, no embate formado entre o Poder Executivo e o Poder Judiciário e sua ação direta na formação de novos valores dentro dessa mesma sociedade.

Quando há referência no cumprimento de necessidades do ser, não se pode dissociar a problemática das políticas públicas que atuam diretamente na realização de direitos fundamentais, sendo que foram altamente positivados na Carta Política de 1988, fazendo o Estado passar de provedor da justiça a Estado julgado. ${ }^{2}$

\footnotetext{
${ }^{1}$ Advogada, procuradora municipal, docente de graduação e pós-graduação, especialista em direito público e mestranda em direito pela URI-Santo Ângelo. Email: cassiana@netvisual.com.br.

${ }^{2}$ GARAPON, Antoine. O juiz e a democracia: o guardião das promessas. Tradução: Maria Luiza de Carvalho. 2. ed. Rio de Janeiro: Renavan, 1999. p. 42.
} 
O Estado contemporâneo sofreu influência direta do Estado liberal do seu ideal advindo da Revolução Francesa, assim como, em segundo momento histórico dos fundamentos do Estado social, com a busca pelo bem estar, decorrente das reivindicações das classes de trabalhadores. Dessa forma, pode-se chegar até ao Estado nos moldes hoje conhecidos, em que estão inseridos os atores de uma sociedade que busca e almeja muito dele, e, que por inúmeras vezes, pelas causas mais variadas vê-se abandonado na realização dos fins principais.

A sociedade brasileira formada no período pós-Constituição de 1988 anseia pela realização de políticas públicas que atendam suas necessidades mínimas, indispensabilidades essas elencadas de forma singular no corpo constitucional, normas que não possuem natureza programática, mas sim aplicação plena e imediata que deveriam ter por escopo a redução das desigualdades sociais e a proteção da dignidade da pessoa humana.

Mas, o que se viu no correr dos vinte anos da promulgação da Carta Política é a inefetividade da realização de políticas públicas que assegurem um mínimo para uma existência digna de boa parte da sociedade. Ressalte-se que tal situação surge pelos motivos mais diversos, sejam eles de ordem econômica, política ou administrativa.

Nesse diapasão, a sociedade inicia a busca da realização de tais direitos na via judicial. Assim o Poder Judiciário passa a exercer um papel até então pertencente aos demais poderes constituídos, e nesse ponto passam a surgir indagações: Pode o magistrado no uso de suas atribuições realizar políticas públicas, mesmo quando os recursos orçamentários são limitados? Pode o agente do Poder Judiciário apontar ao agente do Poder Executivo quem deva ou não atender, elegendo prioridades individuais?

A busca por equilíbrio tem sido a grande incógnita dos estudos atuais; e, como indaga Streck: "qual a relação entre o Direito e a Política? Em que medida o Direito, estabelecido no texto constitucional pode estabelecer ' o construir' da sociedade?"3

\footnotetext{
${ }^{3}$ STRECK, Lênio Luiz. Jurisdição constitucional e hermenêutica: uma nova crítica do direito. Porto Alegre: Livraria do Advogado, 2002. p. 128.
} 
Por vezes, as decisões emanadas do judiciário formam uma linha de tensão no sistema tripartite e suposta autonomia dos poderes. Nesse viés político/jurídico, surge uma nova ordem social na qual os atores buscam bem mais que a realização dos direitos fundamentais individuais, mas também o bem-estar de toda a coletividade.

Essa mudança de paradigmas é inexoravelmente a demonstração da evolução do próprio Estado Contemporâneo, vez que a Constituição de 1988 referenda alguns conteúdos que nos conduzem a compreendê-los como inserida no rol daquele constitucionalismo cujo objeto fundante está nos direitos humanos, conjugados no espectro do princípio da dignidade da pessoa, os quais devem orientar não apenas o trabalho dos juristas como também a atuação das autoridades públicas e da sociedade como um todo. ${ }^{4}$

A jurisprudência e a doutrina têm trazido contribuições inúmeras para a matéria, mas as tentativas de atribuir respostas objetivas ao tema foram até o momento infrutíferas frente à divergência de opiniões, dando ao mesmo sempre uma postura atual. E é com esse intuito que o presente trabalho irá se desenvolver, sem qualquer pretensão de esgotar o assunto, mas sim de provocar possíveis respostas, sem exaurir as possibilidades.

\section{Do estado liberal ao estado contemporâneo}

O Estado, na forma como se conhece atualmente, é um abarcado de inúmeras influências, sejam elas políticas, societárias, culturais, religiosas, comerciais e tantas outras formas de ingerência no governo atuante a época dos acontecimentos.

Lembra Bonavides que, do século XVIII ao século XX, o mundo passou por duas grandes revoluções - a da liberdade e a da igualdade - seguidas de outras duas, uma a revolução da fraternidade, tendo por objeto o homem, e a revolução do Estado social em sua fase mais recente de concretização constitucional, tanto da liberdade como da igualdade. ${ }^{5}$

\footnotetext{
${ }^{4}$ MORAIS, José Luis Bolzan de. Globalização, direitos humanos e constituição: notas para reflexão! In: SANTIN, Janaína Rigo, PILAU SOBRINHO, Liton Lates (Org.). Constituição e política. Passo Fundo: UPF, 2006. p. 88.

${ }^{5}$ BONAVIDES, Paulo. Do estado liberal ao estado social. 7. ed. São Paulo: Malheiros, 2004. p. 29.
} 
Diante dessa evolução, não se pode excluir do cenário contextual o principal ator, qual seja, o cidadão, que por suas lutas e necessidades e a busca de satisfação de seus interesses diretamente junto ao ente governamental, tem papel específico na evolução narrada, vez que, inicialmente, via-se a sociedade totalmente distante da política, e hoje há pleno comprometimento entre ambos os aspectos.

O abandono dos ideais monárquicos, por já não possuírem mais identificação com a sociedade que se formava, trouxe a "revolta" do proletariado que se alavanca contra um sistema superado. Assim, a burguesia, com seus ideários de liberdade, fraternidade e igualdade, traz o Estado liberal que, como conceitua J. J. Canotilho, englobava o liberalismo político, ao qual estavam associadas as doutrinas de direitos humanos e divisão dos poderes e o liberalismo econômico caracterizado pela livre economia do mercado capitalista ${ }^{6}$.

A fase evolutiva é historicamente caracterizada pelos direitos de primeira geração, nos quais, bastava o Estado garantir o direito (liberdades negativas) com a mínima interferência do ente público, tendo por titular o indivíduo. Os direitos eram oponíveis ao Estado, traduzindo-se como faculdades ou atributos da pessoa. A ostentação de uma subjetividade é seu traço mais característico ${ }^{7}$.

A Declaração de Direitos do Homem e do Cidadão passou a ter natureza de direitos históricos, como muito bem ilustrou Bobbio "são direitos nascidos em certas circunstâncias, caracterizadas por lutas em defesa de novas liberdades contra velhos poderes, e nascidos de forma gradual, não todos de uma vez e nem de uma vez por todas". ${ }^{\circ}$

Com o sistema evolutivo dos atores sociais, novas necessidades passaram a exigir um Estado mais intervencionista e atuante em todos os ramos de atividade, assegurando direitos mínimos, mas sem deslocar ao segundo plano as conquistas já efetivadas com as garantias de liberdade do Estado liberal, chegando-se, dessa forma, ao Estado Social.

\footnotetext{
${ }^{6}$ CANOTILHO, José Joaquim Gomes. Direito constitucional e teoria da constituição. 7. ed. Coimbra: Almeida, 2000. p. 109.

${ }^{7}$ BONAVIDES, Paulo. Curso de direito constitucional. 18. ed. São Paulo: Malheiros, 2006. p. 563-564.

${ }^{8}$ BOBBIO, Norberto. A era dos direitos. Rio de Janeiro: Campus, 1992. p. 5.
} 
Como leciona Bolzan, a história dessa passagem, de todos conhecida, vincula-se em especial na luta dos movimentos operários pela conquista de uma regulação /garantização/promoção para a convencional chamada questão social ${ }^{9}$. Nesse instante surgem os direitos de segunda geração, os direitos de igualdade (direitos culturais, sociais e econômicos - conteúdos positivos).

Passou-se do Estado mínimo para o Estado intervencionista, surgindo a figura do Welfare State que, cediço, jamais teria sido implementado na sua forma original no Brasil.

Nessa ordem, direitos e garantias fundamentais do homem devem ser realidades, principalmente pela positivação constitucional, e inúmeras decorrências desse liame estrutural estabelecido passam a fazer parte do dia a dia não só do gestor público, mas de toda sociedade constituída.

Assim inicia-se o revés do Estado, que ultrapassa o Estado social e vai de encontro ao Estado contemporâneo. As demandas sociais com fins de garantir os direitos mínimos preconizados nas Cartas Políticas passam a surgir com urgência ímpar e nas formas mais diversificadas, mas sem que o gestor possa dar plena efetividade a todos, na mesma proporção, passando-se a um ambiente crítico.

Hoje, sob o influxo do chamado Estado democrático de direito, está-se imerso ao mesmo tempo num projeto de transformação da sociedade, por um lado, e por outro, num esfacelamento das condições necessárias e suficientes para a sua concretização. ${ }^{10}$

Desaparece o caráter assistencial, caritativo da prestação de serviços e passam a ser vistos como direitos próprios da cidadania, inerentes ao pressuposto da dignidade da pessoa humana, constituindo, assim, um patrimônio do cidadão ${ }^{11}$; e tal situação igualmente é vislumbrada no Brasil.

Especificamente, reportando-se ao Estado brasileiro, reconhece Bonavides que ele é, portanto, de terceira geração, em face desses aperfeiçoamentos. Um Es-

\footnotetext{
9 MORAIS, José Luiz Bolzan de. As crises do estado e da constituição e a transformação espacial dos direitos humanos. Porto Alegre: Livraria do Advogado, 2002. p. 34-35.

${ }^{10}$ Ibidem, p. 82.

${ }^{11}$ MORAIS, José Luiz Bolzan de et al. O estado e suas crises. Porto Alegre: Livraria do Advogado, 2005. p. 18.
} 
tado que não concede apenas direitos sociais básicos, mas os garante, assim como delimita o doutrinador:

o verdadeiro problema do Direito Constitucional de nossa época está, a nosso ver, em como juridizar o Estado social, como estabelecer e inaugurar novas técnicas ou institutos processuais para garantir os direitos sociais básicos, a fim de fazê-los efetivos. ${ }^{12}$

Também não se pode ser olvidado que a nossa República se apresenta como um Estado social e democrático de direito, cujo contornos básicos se encontram ancorados no preâmbulo, nas normas dos artigos $1^{\circ}$ ao $4^{\circ}$ da CF (princípios fundamentais), pela consagração expressa de um catálogo de direitos fundamentais sociais (arts. $6^{\circ}$ ao $11^{\circ}$ ) e em fase dos princípios norteadores dos títulos que versam sobre as ordens econômica e social (arts. 170 e 193), isso sem falar nas diversas normas concretizadoras desses princípios que se encontram dispersas pelo texto constitucional. ${ }^{13}$

Destarte, os direitos sociais mínimos, constitucionalmente protegidos, para uma existência digna dos atores sociais somente podem ser considerados realizados através de políticas públicas efetivas e de caráter universal, onde a maioria socieária possa ter acesso, com qualidade de serviços, com fins de que os direitos de liberdade e igualdade e todas as demais gerações possam ser plenamente constituídas perante a sociedade e o próprio Estado gestor.

\section{As políticas públicas no Brasil pós-1988}

O projeto constitucional que foi idealizado para o Brasil no período pós-ditadura teve como ponto culminante a promulgação da "Carta Cidadã” que passou a trazer em seu corpo inúmeros direitos e garantias, explicitando-os e vinculandoos ao Estado e a toda sociedade como gestores.

A realização dos fundamentos da República Federativa do Brasil, elencados no artigo $1^{\circ}$. da Carta Máxima, que incorporam, dentre outros, a cidadania e a dignidade da pessoa humana e os fundamentos do artigo $3^{\circ}$, a construção de uma

\footnotetext{
${ }^{12}$ BONAVIDES, Paulo. Curso de direito constitucional. 18. ed. São Paulo: Malheiros, 2006. p. 373.

${ }^{13}$ SARLET, Ingo Wolfgang. A eficácia dos direitos fundamentais. Porto Alegre: Livraria do Advogado, 1998. p. 86.
} 
sociedade livre, justa e solidária, que preze pela erradicação da pobreza e a redução das desigualdades, dependem em muitas vezes de políticas públicas efetivas.

Certo de que na forma que tem sido conduzido pelos administradores, a realização desses direitos básicos tem tomado um caráter de mero favor ao ator principal e não como um direito constituído, esquecendo-se o aplicador que direitos fundamentais não possuem caráter programático, mas sim aplicação imediata que irá materializar na grande maioria das vezes por meio da atividade administrativa.

De forma prestimosa, Rogério Gesta Leal conceitua políticas públicas como sendo a ação estratégica (de instituições ou pessoas de direito público) que visa atingir fins previamente determinados por finalidades, objetivos e princípios de natureza pública. Tal ação, inexoravelmente, vem marcada por altos níveis de racionalidade programática, caracterizada por medidas organizacionais e de planejamento. ${ }^{14}$

A sociedade até pouco tempo apresentou um caráter de apatia frente à atividade estatal e também sobre a omissão produzida pelo mesmo ente. Ocorre que um despertar decorrente das necessidades criadas pela sua própria evolução e por motivos ligados diretamente à escassez, à diminuição da renda e a demais conflitos coletivos, muitos deles decorrentes da globalização e da atuação direta das empresas transnacionais na ordem jurídica e econômica do sistema, fez com que certos padrões fossem revistos.

Nesse contexto, a busca pela realização dos direitos insculpidos na Constituição é transferida do Poder Executivo para o Poder Judiciário, como discorre Garapon, a mutação do Estado provedor e a fragilidade do homem democrático dão ao direito o papel de protagonista. ${ }^{15}$

Continua o doutrinador europeu alegando que o juiz passa a ser o último guardião de promessas tanto para o sujeito como para a comunidade política. Por não conservarem a memória viva dos valores que os formam, eles confiam à justiça a guarda de seus juramentos. ${ }^{16}$

\footnotetext{
${ }^{14}$ LEAL, Rogério Gesta. O controle jurisdicional de políticas públicas no Brasil: possibilidades materiais. In: SARLET, Ingo Wolfgang (Coord.). Jurisdição e direitos fundamentais: anuário 2005/2006. Porto Alegre: Escola Superior de Magistratura; Livraria do Advogado, 2006. p. 161.

${ }^{15}$ GARAPON, Antoine. O juiz e a democracia: o guardião das promessas. Tradução: Maria Luiza de Carvalho. 2. ed. Rio de Janeiro: Renavan, 1999. p. 27.

${ }^{16}$ Ibidem, p. 27.
} 
No Estado provedor, que deveria ter como objetivo primordial tudo suprir e a todos atingir, quando as ações esperadas são frustradas, o cidadão busca a realização dessas mesmas necessidades junto à justiça, passando-se diretamente a judicialização das políticas públicas.

A interferência do Poder Judiciário na realização de tarefas originariamente relegadas ao Poder Executivo redefine a relação entre os três poderes, adjudicando ao Poder Judiciário funções de controle dos poderes políticos. ${ }^{17}$

A conclusão que se pode ter é que não foi o juiz que se tornou um novo ator político, mas foram os políticos que perderam sua imunidade em relação à justiça, ${ }^{18}$ e tal fato ocorre diretamente por terem os sujeitos eleitos democraticamente abandonado seus primordiais princípios de realização dos fins do Estado e do interesse público que são em si mesmos os fins e o interesse de toda sociedade.

Nas palavras de Juarez Freitas, o princípio do interesse público exige a "simultânea subordinação das ações administrativas à dignidade da pessoa humana e o fiel respeito aos direitos fundamentais". ${ }^{19}$

A dignidade humana num sistema democrático deve ter por base direta uma organização que serve o cidadão, mas jamais o contrário; a ideia de Estado Democrático de Direito, como o próprio tema da Democracia, passa pela avaliação da eficácia e legitimidade dos procedimentos utilizados no exercício de gestão dos interesses públicos e sua própria demarcação, a partir de novos comportamentos institucionais e novos instrumentos políticos de participação que expandam como prática histórica a dimensão democrática da construção social de uma cidadania contemporânea. ${ }^{20}$

E, quando o legislador/administrador abandona os ditames supracitados, cabe ao magistrado, na figura de um colegislador permanente, assegurar

\footnotetext{
${ }^{17}$ VIANNA, Luiz Werneck. A judicialização da política e das relações sociais no Brasil. Rio de Janeiro: Renavan, 1999. p. 21.

${ }^{18}$ GARAPON, Antoine. O juiz e a democracia: o guardião das promessas. Tradução: Maria Luiza de Carvalho. 2. ed. Rio de Janeiro: Renavan, 1999. p. 35.

${ }^{19}$ FREITAS, Juarez. O controle dos atos administrativos e os princípios fundamentais. 3. ed. São Paulo: Malheiros, 2004. p. 36.

${ }^{20}$ LEAL, Rogério Gesta. O controle jurisdicional de políticas públicas no Brasil: possibilidades materiais. In: SARLET, Ingo Wolfgang (Coord.). Jurisdição e direitos fundamentais: anuário 2005/2006. Porto Alegre: Escola Superior de Magistratura; Livraria do Advogado, 2006. p. 172-173.
} 
que essas eleições sejam postas em prática mesmo que coativamente, pois vai atribuir status de realidade a norma positivada.

A justiça se torna um espaço de exigibilidade da democracia. Ela oferece potencialmente a todos os cidadãos a capacidade de interpelar seus governantes, de tomá-los ao pé da letra e de intimá-los a respeitarem as promessas contidas na lei. ${ }^{21}$

Por fim, é de considerar de forma conclusiva, mas jamais absoluta que as garantias constitucionais somente poderão ser realizadas por meio de políticas públicas efetivas e de caráter universal para que assim a preconizada dignidade possa ser alcançada e, quando abandonadas por quem originariamente teria a função de realizá-las, cabe à sociedade exigir do Poder Judiciário, que possui plena legitimidade de interferir.

Mas, nesse nível de busca por respostas, as dúvidas passam a ser geradas, sendo um grande campo de discussão saber se tal poder realmente seria ilimitado e, em caso de resposta negativa, quais seriam esse limites de restrição da atuação do "poder julgador" cabendo assim, uma análise direta sobre o tema.

\section{Direitos sociais, mínimo existencial e reserva do possível}

A realização eficaz dos direitos sociais é uma das questões mais discutidas nos dias atuais e, por consequência lógica sua inefetividade, é um dos maiores fatores na caracterização da crise do Estado contemporâneo. Como já exposto, a garantia da igualdade material permite ao indivíduo não só o direito de sobrevivência, mas de integração completa na sociedade.

Tem-se como definição máxima que de nada ou pouco adianta a positivação constitucional de um rol de liberdades sem a correspondente garantia de realização de um mínimo necessário para a vida humana.

Frente à situação atual da sociedade nacional e do cenário político vivenciado, a opulência e a escassez dos recursos orçamentários até mesmo

${ }^{21}$ GARAPON, Antoine. O juiz e a democracia: o guardião das promessas. Tradução: Maria Luiza de Carvalho. 2. ed. Rio de Janeiro: Renavan, 1999. p. 49. 
para a realização desses direitos mínimos enfrentam sérias restrições e cada vez uma gama maior de doutrinadores tem levantado a possibilidade da sistemática da reserva do possível ser aplicada de forma plena, principalmente quando o Estado se encontrar no divã do Poder Judiciário por não ter implementado direitos sociais mesmo que para preservar o mínimo existencial.

Em se considerando as limitações econômicas à efetivação dos direitos sociais, os estudiosos passaram a sustentar que mesmo a busca por esses direitos estaria condicionado ao que se determinou chamar de reserva do possível.

"Reserva do possível" é um conceito nascido na Corte Constitucional alemã quando do julgamento de lide onde se firmou posicionamento de que "estão sujeitos à reserva do possível no sentido daquilo que o indivíduo, de maneira racional, pode esperar da sociedade". ${ }^{22}$

Assim, passou-se a entender que se faz necessário não apenas que a norma outorgue certa capacidade de atuação para o seu destinatário como também existam recursos materiais que tornem possível a satisfação do direito, fatores que consubstanciam a cláusula da reserva do possível. ${ }^{23}$

A toda essa problemática criada que aliada à falta de ação do Estado, que deveria se apresentar de forma prestacional como forma de garantir direitos sociais mínimos, traz a necessidade de que o governante venha severamente a ponderar, diante do caso concreto, para que possa chegar à resposta de quais devem ser os critérios utilizados para definir o que é razoável.

Nesse momento, há de se trazer à discussão que a existência de um direito mínimo de existência extraído, na Alemanha, do princípio da dignidade humana, ${ }^{24}$ cabendo, como já dantes comentado, ao Estado a garantia de um mínimo existencial para cada indivíduo.

\footnotetext{
${ }^{22}$ KRELL, Andreas. Controle judicial dos serviços públicos na base dos direitos fundamentais sociais. In: SARLET, Ingo Wolfgang (Org.). A Constituição concretizada: construindo pontes entre o público e o privado. Porto Alegre: Livraria do Advogado, 2000. p. 36-40.

${ }^{23}$ SARLET, Ingo Wolfgang. Os direitos fundamentais sociais na Constituição de 1988. Porto Alegre: Livraria do Advogado, 2001. p. 150-152.

${ }^{24}$ Ibidem, p. 36-40.
} 
Com relação ao tema, que apesar de difícil definição e abrangência, vez que o mínimo de um sujeito e diverso de outro, principalmente se levadas em consideração as condições externas e internas que interferem na vida de cada pessoa, parte-se da ideia do mínimo necessário para salvaguardar uma existência humana digna.

Ensina Ricardo Lobo Torres que:

O mínimo é direito subjetivo protegido negativamente contra a intervenção do Estado e, ao mesmo tempo, garantido positivamente pelas prestações estatais. Diz-se, pois, que é direito de status negativus e de status positivus, sendo certo que não raro se convertem uma na outra ou se complicam mutuamente a proteção constitucional positiva e a negativa. ${ }^{25}$

Para Alexy, o mínimo existencial poderia ser garantido, isto é, apenas direitos sociais, econômicos e culturais considerados mais relevantes, em face do caso concreto por integrarem o núcleo da dignidade da pessoa ou por decorrerem do direito básico da liberdade, impor-se-iam erga ommes e seriam diretamente sindicáveis. ${ }^{26}$

Em uma grata tentativa de trazer alento à parte da problemática, Rogério Gesta Leal identificou como políticas públicas constitucionais vinculantes, aqui entendidas como aquelas ações que o texto político atribui aos Poderes Estatais como efetivadoras de direitos e garantias fundamentais, e todas as decorrentes delas, haja vista os níveis compartidos de responsabilidades entre as entidades federativas brasileiras e a cidadania, envolvendo a matéria. ${ }^{27}$

Para o doutrinador, tais ações são independentes da vontade ou discricionariedade estatal para que venham a acontecer, eis que condizentes a direitos indisponíveis e da mais alta importância e emergência comunitárias, perquirindo ime-

${ }^{25}$ TORRES, Ricardo Lobo. Tratado de direito constitucional financeiro e tributário: os direitos humanos e a tributação: imunidades e isonomia. Rio de Janeiro: Renovar, 2005. v. 3. p. 164.

${ }^{26}$ ALEXY, Robert. Colisão e ponderação como problema fundamental da dogmática dos direitos. Revista Fundação Casa de Rui Barbosa, Rio de Janeiro, v. 34, p. 39, 1998.

${ }^{27}$ LEAL, Rogério Gesta. O controle jurisdicional de políticas públicas no Brasil: possibilidades materiais. In: SARLET, Ingo Wolfgang (Coord.). Jurisdição e direitos fundamentais: anuário 2005/2006. Porto Alegre: Escola Superior de Magistratura; Livraria do Advogado, 2006. p. 167. 
diata materialização, sob pena de comprometer a dignidade humana e o mínimo existencial dos seus carecedores. ${ }^{28}$

Na teoria do mínimo existencial é de se destacar que há um direito às condições mínimas de existência humana digna que não pode ser objeto de intervenção do Estado e que ainda exige prestações estatais positivas. ${ }^{29}$

Frente às inúmeras tentativas de atribuir limites a atividade jurisdicional quando chamado pelo clamor público a proteger direitos sociais abandonados pelo gestor, principalmente quando para atender àquele mínimo existencial que salvaguarda a dignidade do ser, deve-se ter em mente que o magistrado, mais do que ninguém, deve levar em consideração o caso singular a ser analisado, pois muitas vezes uma decisão pode inviabilizar toda prestação dos demais serviços que possuem igual importância.

A lição de Garapon recorda que o juiz goza de total irresponsabilidade política sendo às restrições econômicas estranhas, ${ }^{30} \mathrm{e}$, nesse diapasão, o respeito ao orçamento anual e ao plano plurianual, e, com a comprovação de que de maneira geral a prestação dos direitos sociais está-se dando da única forma a ser exigida do gestor, a proposta alemã da reserva do possível poderá ser plenamente aplicada ao sistema nacional.

Mas, não se pode ser olvidado que, quando não abarca a realização o mínimo existencial, no tocante às demais necessidades humanas, a via legítima é a alocação via recursos orçamentários:

Com efeito, quanto mais diminuta a disponibilidade de recursos, mais se impõe uma deliberação responsável a respeito de sua destinação, o que nos remete diretamente à necessidade de buscarmos o aprimoramento dos mecanismos de gestão democrática do orçamento público, além de uma crescente conscien-

${ }^{28}$ LEAL, Rogério Gesta. O controle jurisdicional de políticas públicas no Brasil: possibilidades materiais. In: SARLET, Ingo Wolfgang (Coord.). Jurisdição e direitos fundamentais: anuário 2005/2006. Porto Alegre: Escola Superior de Magistratura; Livraria do Advogado, 2006. p. 168-169.

${ }^{29}$ TORRES, Ricardo Lobo. O mínimo existencial e os direitos fundamentais. Revista de Direito Administrativo, Rio de Janeiro, v. 177, p. 29-49, 1989.

${ }^{30}$ GARAPON, Antoine. O juiz e a democracia: o guardião das promessas. Tradução: Maria Luiza de Carvalho. 2. ed. Rio de Janeiro: Renavan, 1999. p. 73. 
tização por parte dos órgãos do Poder Judiciário, que não apenas podem como devem zelar pela efetivação dos direitos fundamentais sociais, mas ao fazê-lo haverão de obrar com a máxima cautela e responsabilidade, seja ao concederem, ou não, um direito subjetivo a determinada prestação social, seja quando declararem a inconstitucionalidade de alguma medida restritiva e/ou retrocessiva de algum direito social. Neste sentido (e desde que assegurada atuação dos órgãos jurisdicionais, quando e na medida do necessário) efetivamente há que dar razão a Holmes e Sunstein quando afirmam que "levar direitos a sério (especialmente pelo prisma da eficácia e efetividade) é levar a sério o problema da escassez." ${ }^{31}$

De tal entendimento não compartilha J. J. Canotilho, que considera desoladora a tese de que a realização dos direitos sociais está intimamente ligada aos "cofres cheios”, e a figura do mínimo existencial viria para atenuar tal constatação, com fins de que a dignidade da pessoa seja protegida. ${ }^{32}$

Frente a todo exposto, há de se concluir que a positivação dos direitos sociais, com fim único da realização da dignidade humana, como sendo um dos fins do Estado Democrático de Direito, que tem como destinatário o verdadeiro ente detentor da soberania, o povo, deve ser albergada, senão pelo executivo e legislativo, mas também pelo judiciário como última instância de recurso da sociedade.

Quando os legitimados ao direito de gestão que exercem seus mandatos outorgados pelo voto popular abandonam a sociedade que legitima toda sua existência, cabe ao Poder Judiciário, frente à realidade apresentada por ambas as partes envolvidas no pleito que se instala, analisar todas as nuance, sempre levando em consideração não somente o interesse individual mas também o de toda coletividade.

\section{Conclusões}

Assim, após todo o descrito, podemos chegar a algumas conclusões, que estão longe de ser uma máxima sem direito a contestação, visto que nem mesmo esse é o

\footnotetext{
${ }^{31}$ HOLMES, Stephen; SUSTEIN, Cass R. apud SARLET, Ingo Wolfgang. A eficácia dos direitos fundamentais. Porto Alegre: Livraria do Advogado, 1998. p. 349.

${ }^{32}$ CANOTILHO, José Joaquim Gomes. Direito constitucional e teoria da constituição. 7. ed. Coimbra: Almeida, 2000. p. 481.
} 
objetivo do trabalho, mas tentar sem maiores expectativas deixar o tema vivo dentro da sociedade.

É inegável a participação do Estado, enquanto pessoa jurídica de Direito Público na vida social, bem como é indiscutivelmente grande em todos os momentos da cultura ocidental, principalmente após a Segunda Guerra Mundial ${ }^{33}$, quando esse Estado deixa de suprir as necessidades dos seus para a consecução de um mínimo de dignidade e autoriza a intervenção judicial.

A preservação desses direitos mínimos tem, no tocante à camada mais desprivilegiada da população, que originariamente possui menor acesso na busca de direitos, extrema importância, vez que dependem da gestão pública para a realização de necessidades básicas, dentre elas até mesmo o direito do acesso ao judiciário para a preservação dessas garantias fundamentais.

A prática da judicialização das políticas tem sido o caminho mais utilizado pela sociedade do Estado contemporâneo quando deixa de cumprir seus objetivos e princípios, sendo que os atos administrativos precisam ser praticados e controlados desde uma ótica mais compatível com os tempos em que se reivindica um direito administrativo dialógico e persuasivo, bem como um Estado matizado por uma atuação substancialmente compatível com a afirmação crescente do núcleo essencial dos direitos fundamentais, na construção de uma ordem justa ou, pelo menos, não tão assimétrica." ${ }^{34}$

Mas não se pode desconsiderar que tal fato pode ter resultados nefastos, dependendo da forma em que for encarada. Ocorre que, na ânsia de realizar o projeto constitucional, principalmente no tocante à valorização dos direitos fundamentais e o mínimo existencial, esquece o julgador de ponderar sobre o todo, por sua total desnecessidade de cumprir com a responsabilidade pela gestão do orçamento anual e o plano plurianual do ente público, sendo que uma simples decisão que abarca o direito de um poderá pôr em risco todo sistema prestacional da coletividade, surgindo assim a figura da "reserva do possível" como contraponto a essa discussão e que não pode ser abandonado no momento da avaliação do caso concreto.

${ }^{33}$ LEAL, Rogério Gesta. Estado, administração pública e sociedade: novos paradigmas. Porto Alegre: Livraria do Advogado, 2006. p. 29.

${ }^{34}$ FREITAS, Juarez. O controle dos atos administrativos e os princípios fundamentais. 3. ed. São Paulo: Malheiros, 2004. p 232- 233. 
Os juízes existiam antes que as leis fossem criadas. Esses juízes, naquele tempo de ignorância e barbárie, eram ministros de equidade entre os homens - ainda o são quando não dirigidos por leis escritas. Não podem, portanto, sob o pretexto da obscuridade e do silêncio das leis, interromper arbitrariamente suas atuações. ${ }^{35}$

Assim, o encontro de um sistema de "freios e contrapesos" entre os poderes constituídos e a própria sociedade, para que, com uma atuação conjunta possa agir com ponderação a fim de que todos os atores envolvidos tenham acesso à tão almejada concretização do projeto constitucional e, por conseguinte, dos direitos sociais, ressalvando aqueles que têm status de direito fundamental.

Nesse sentido, a constituição tem papel primordial, devendo ser reportada à proposta da Constituição Dirigente, modelo concebido pelo constitucionalista português J. J. Gomes Canotilho, e que é, em rápidas palavras, uma Constituição que se propõe a transformar a realidade social, por meio de uma maciça intervenção do Estado nas atividades dos particulares e na positivação de um extenso rol de direitos e garantias institucionais. ${ }^{36}$ A Constituição Brasileira no modelo original promulgado em 1988, antes das reformas que se seguiram, pode ser considerada um típico caso de Constituição Dirigente.

O Estado brasileiro deve utilizar-se dos exemplos decorrente da evolução mundial para a preservação dos direitos fundamentais e, por consequência da realização do mínimo necessário a uma existência digna, nesse sentido, pode ser citado o direito comparado alemão, como noticia Alexandre Cunha. ${ }^{37}$ "A jurisprudência constitucional alemã vem interpretando a dignidade humana como sendo, além de direito fundamental, programa constitucional e princípio de base do Estado de Direito".

Há de se avaliar que o todo do Estado deve ser preservado e nesse sentido a nova sociedade que se forma frente a esse vale profundo tem o compromisso de

${ }^{35}$ PORTALIS. Discurso pronunciado em 14 de dezembro de 1801 para a discussão do título preliminar do Código Civil.

${ }^{36}$ CANOTILHO, José Joaquim Gomes. Direito constitucional e teoria da constituição. 7. ed. Coimbra: Almeida, 2000. p. 365.

${ }^{37}$ CUNHA, Alexandre dos Santos. Dignidade da pessoa humana: conceito fundamental do direito civil. In: MARTINS-COSTA, Judith. A Reconstrução do direito privado: reflexos dos princípios, diretrizes e direitos fundamentais constitucionais no direito privado. São Paulo: Revista dos Tribunais, 2002. p. 248. 
ser atuante de tal maneira a exigir e fiscalizar a efetivação desses direitos mínimos, formando-se assim uma nova consciência evolutiva que exige de todos os poderes constituídos a efetivação de seus direitos fundamentais individuais, mas sem abandonar o direito à dignidade de toda coletividade.

É de assegurar que a realização daquela dignidade humana preconizada num sistema democrático deve ter por base direta uma organização que serve ao cidadão, mas jamais privilegiar o contrário. A ideia de Estado Democrático de Direito, como o próprio tema da Democracia, passa pela avaliação da eficácia e legitimidade dos procedimentos utilizados no exercício de gestão dos interesses públicos e sua própria demarcação, a partir de novos comportamentos institucionais e novos instrumentos políticos de participação que expandam, como prática histórica, a dimensão democrática da construção social de uma cidadania contemporânea. ${ }^{38}$

Tal proposta não está isenta de críticas e por tal motivo a conclusão lógica é que o Estado contemporâneo deve rigorosamente observar a preservação dos direitos fundamentais em todas as suas gerações (as hoje conhecidas e as que estão por vir), que fortaleça todas as esferas de poder para que a realização do bem comum da sociedade, no qual todos realmente possam ser iguais em direitos e obrigações, com as mesmas oportunidades de desenvolvimento e crescimento, e que as ações governamentais atinjam todos os níveis sociais.

As palavras de Ricardo Lobo Torres não podem ser deslocadas do presente trabalho, uma vez que recordam que a dignidade humana e as condições materiais da existência não podem retroceder aquém de um mínimo, do qual nem os prisioneiros, os doentes mentais e os indigentes podem ser privados. ${ }^{39}$

A imbricação ocorrida entre sociedade, poderes constituídos, necessidades mínimas e a realidade, que muitas vezes não é a sonhada por todos, traz

\footnotetext{
${ }^{38}$ LEAL, Rogério Gesta. O controle jurisdicional de políticas públicas no Brasil: possibilidades materiais. In: SARLET, Ingo Wolfgang (Coord.). Jurisdição e direitos fundamentais: anuário 2005/2006. Porto Alegre: Escola Superior de Magistratura; Livraria do Advogado, 2006 p. 172-173.

${ }^{39}$ TORRES, Ricardo Lobo. A cidadania multidimensional na era dos direitos. In: TORRES, Ricardo Lobo (Org.). Teoria dos direitos fundamentais. 2. ed. Rio de Janeiro: Renovar, 2001. p. 267.
} 
uma direta evolução não só do ser, mas de todo ambiente em que vive. Traz em si a construção de uma nova ordem social, não tão individualista, mas que busca a realização do bem e do progresso coletivo no cumprimento imediato dos direito mínimos.

Em última análise, a sociedade atua dentro desse cenário como protagonista, formando novos paradigmas, nos quais nenhum dos poderes constituídos pela própria Constituição, seja o Legislativo, o Executivo ou mesmo o Judiciário pode agir sob o manto da discricionariedade de forma arbitrária. Seus atos estão sujeitos ao controle social, considerado hoje um das formas mais efetivas de verificação, principalmente quando a matéria envolvida for a realização de direitos fundamentais.

\title{
The contemporary state, the court activity and the implementation of public policies: the (re)construction of a social reality
}

\begin{abstract}
The contemporary state faces problems of effectiveness which often come in the form of provision of services to ensure that minimum of dignity to the citizens under its jurisdiction, this provider system often can be solved through public policies that front to a Provider State inadequate and the increase vertiginous passes demands of the "state-judged", and the limits of that trial are inserts in letters policies of each state as a form of limits and possibilities.
\end{abstract}

Keywords: State. Public policies. Dignity. Citizens.

\section{Referências}

ALEXY, Robert. Colisão e ponderação como problema fundamental da dogmática dos direitos. Revista Fundação Casa de Rui Barbosa, Rio de Janeiro, v. 34, p. 39, 1998.

BOBBIO, Norberto. A era dos direitos. Rio de Janeiro: Campus, 1992.

BONAVIDES, Paulo. Curso de direito constitucional. 18. ed. São Paulo: Malheiros, 2006. 
. Do Estado liberal ao Estado social. 7. ed. São Paulo: Malheiros, 2004.

CANOTILHO, José Joaquim Gomes. Direito constitucional e teoria da constituição. 7. ed. Coimbra: Almeida, 2000.

CUNHA, Alexandre dos Santos. Dignidade da pessoa humana: conceito fundamental do direito civil. In: MARTINS-COSTA, Judith. A reconstrução do direito privado: reflexos dos princípios, diretrizes e direitos fundamentais constitucionais no direito privado. São Paulo: Revista dos Tribunais, 2002.

FREITAS, Juarez. O controle dos atos administrativos e os princípios fundamentais. 3. ed. São Paulo: Malheiros, 2004.

GARAPON, Antoine. O juiz e a democracia: o guardião das promessas. Tradução: Maria Luiza de Carvalho. 2. ed. Rio de Janeiro: Renavan, 1999.

KRELL, Andreas. Controle judicial dos serviços públicos na base dos direitos fundamentais sociais. In: SARLET, Ingo Wolfgang (Org.). A Constituição concretizada: construindo pontes entre o público e o privado. Porto Alegre: Livraria do Advogado, 2000.

LEAL, Rogério Gesta. Estado, administração pública e sociedade: novos paradigmas. Porto Alegre: Livraria do Advogado, 2006.

. O controle jurisdicional de políticas públicas no Brasil: possibilidades materiais. In: SARLET, Ingo Wolfgang (Coord.). Jurisdição e direitos fundamentais: anuário 2005/2006. Porto Alegre: Escola Superior de Magistratura; Livraria do Advogado, 2006.

MORAIS, José Luiz Bolzan de. As crises do estado e da constituição e a transformação espacial dos direitos humanos. Porto Alegre: Livraria do Advogado, 2002.

Globalização, direitos humanos e constituição: notas para reflexão! In: SANTIN, Janaína Rigo, PILAU SOBRINHO, Liton Lates (Org.). Constituição e política. Passo Fundo: UPF, 2006.

MORAIS, José Luiz Bolzan de et al. O estado e suas crises. Porto Alegre: Livraria do Advogado, 2005.

SARLET, Ingo Wolfgang. A eficácia dos direitos fundamentais. Porto Alegre: Livraria do Advogado, 1998. 
Os direitos fundamentais sociais na Constituição de 1988. Porto Alegre: Livraria do Advogado, 2001.

STRECK, Lênio Luiz. Jurisdição constitucional e hermenêutica: uma nova crítica do direito. Porto Alegre: Livraria do Advogado, 2002.

TORRES, Ricardo Lobo. A cidadania multidimensional na era dos direitos. In: TORRES, Ricardo Lobo (Org.). Teoria dos direitos fundamentais. 2. ed. Rio de Janeiro: Renovar, 2001.

O mínimo existencial e os direitos fundamentais. Revista de Direito Administrativo, Rio de Janeiro, v. 177, 1989.

. Tratado de direito constitucional financeiro e tributário: os direitos humanos e a tributação: imunidades e isonomia. Rio de Janeiro: Renovar, 2005. v. 3.

VIANNA, Luiz Werneck. A judicialização da política e das relações sociais no Brasil. Rio de Janeiro: Renavan, 1999. 
